\title{
Seasonality of snow accumulation at Mount Wrangell, Alaska, USA
}

\author{
Syosaku KANAMORI, ${ }^{1}$ Carl S. BENSON, ${ }^{2}$ Martin TRUFFER, ${ }^{2}$ Sumito MATOBA, ${ }^{3}$ \\ Daniel J. SOLIE, ${ }^{2}$ Takayuki SHIRAIWA ${ }^{4}$ \\ ${ }^{1}$ Graduate School of Environmental Science, Hokkaido University, Sapporo 060-0810, Japan \\ E-mail: kanasyo@lowtem.hokudai.ac.jp \\ ${ }^{2}$ Geophysical Institute, University of Alaska Fairbanks, 903 Koyukuk Drive, Fairbanks, Alaska 99775-7320, USA \\ ${ }^{3}$ Institute of Low Temperature Science, Hokkaido University, Sapporo 060-0819, Japan \\ ${ }^{4}$ Research Institute for Humanity and Nature, 457-4 Motoyama, Kamigamo, Kyoto, 603-8047, Japan
}

\begin{abstract}
We recorded the burial times of temperature sensors mounted on a specially constructed tower to determine snow accumulation during individual storms in the summit caldera of Mount Wrangell, Alaska, USA, $\left(62^{\circ} \mathrm{N}, 144^{\circ} \mathrm{W} ; 4100 \mathrm{~m}\right.$ a.s.l. $)$ during the accumulation year June 2005 to June 2006. The experiment showed most of the accumulation occurred in episodic large storms, and half of the total accumulation was delivered in late summer. The timing of individual events correlated well with storms recorded upwind, at Cordova, the closest Pacific coastal weather station $(200 \mathrm{~km}$ southsoutheast), although the magnitude of events showed only poor correlation. Hence, snow accumulation at Mount Wrangell appears to be a reflection of synoptic-scale regional weather systems. The accumulation at Mount Wrangell's summit ( $>2.5 \mathrm{~m}$ w.e.) exceeded the precipitation at Cordova. Although the direct relationship between accumulation of individual storms at the summit of Mount Wrangell and precipitation events at Cordova may be unique in the region, it is useful for interpreting ice cores obtained on Mount Wrangell. This is especially the case here because the high rate of accumulation allows high time resolution within the core.
\end{abstract}

\section{INTRODUCTION}

Mount Wrangell $\left(62^{\circ} \mathrm{N}, 144^{\circ} \mathrm{W} ; 4317 \mathrm{~m}\right.$ a.s.I.) is part of the Wrangell-St Elias Mountains, located along the Gulf of Alaska (Fig. 1). It is among several mountains in the area that extend into the dry snow facies (Benson, 1968; Partington, 1998). Several ice cores have been obtained from this region to study past climate (Benson, 1984; Holdsworth and others, 1992; Goto-Azuma and others, 2003; Fisher and others, 2004; Shiraiwa and others, 2004; Zagorodnov and others, 2005; Yalcin and others, 2006; Fig. 1). Mount Wrangell is one of these ice-core sites. The high accumulation rate on Mount Wrangell guarantees an ice core with thick annual layers. Near the center of the caldera the averaged annual accumulation rate from 1992 to 2003 was $2.49 \mathrm{~m}$ w.e. (Yasunari and others, 2007) and we recorded $\sim 3.0 \mathrm{~m}$ w.e. $\mathrm{a}^{-1}$ from 2004 to 2006 . These thick annual layers make it possible to interpret the ice core with intraannual resolution. Yasunari and others (2007) assumed that parameters such as stable- isotope peaks, tritium peaks or micro-particle peaks had annual periodicity in the Mount Wrangell core. They discussed the seasonal variation of dust fluxes. Studying the exact timing of such events helps to understand their sources. The seasonal distribution of snowfall is critical for ice-core interpretation. For example, Steig and others (1994) pointed out that changes in precipitation seasonality can change the isotope value of the ice core without any change in temperature. The ice core will only record climate information from wet deposition at the time of the precipitation, which does not necessarily coincide with mean annual conditions. The timing of events within an annual layer cannot be determined, as opposed to the dating of the annual layers themselves. In order to determine the time when snow was deposited and the amount, we recorded accumulation from 3 June 2005 to 22 June 2006 at the summit of Mount Wrangell. Although detailed snow-depth measurements had already been carried out at more than 30 points on the summit of Mount Wrangell in 1961 (Benson, 1968) and in 1965 (Wharton, 1966), the period was limited to 2 months from July to

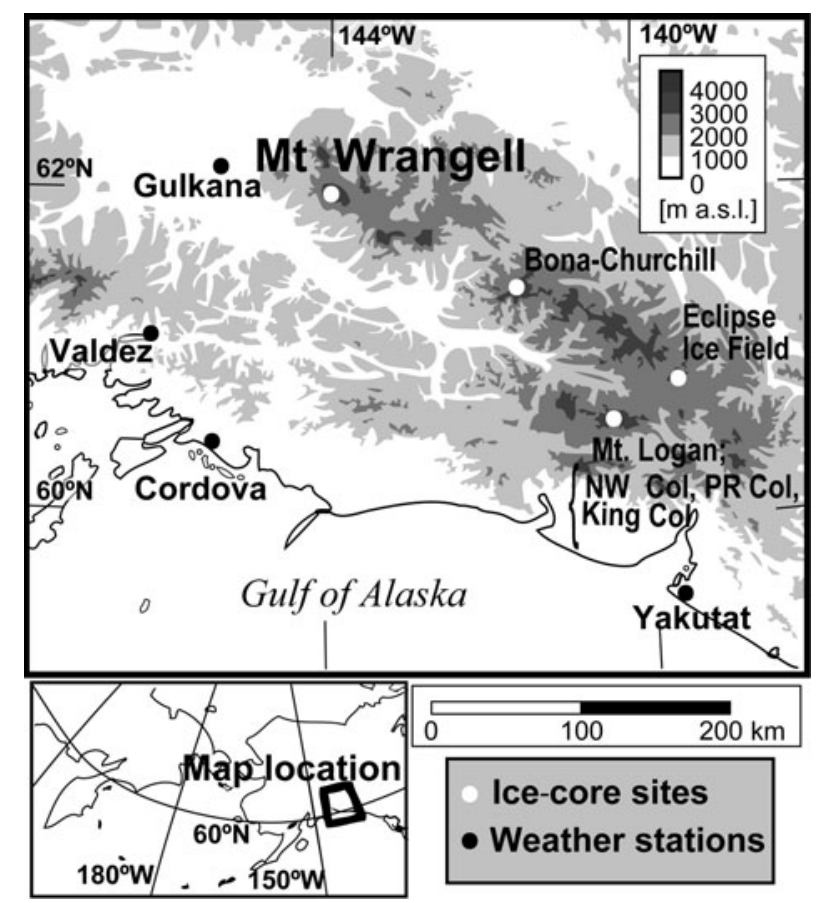

Fig. 1. Map of the Wrangell-St Elias Mountains showing the location of the measurement site at Mount Wrangell $(4100 \mathrm{~m})$ and other ice-core sites and weather stations. The ice-core sites shown include Northwest Col $(5340 \mathrm{~m})$, Prospector-Russell Col (5340 m) and King Col (4135 m) in Mount Logan, Eclipse Ice Field (3017 m) and Bona-Churchill $(4400 \mathrm{~m})$. 


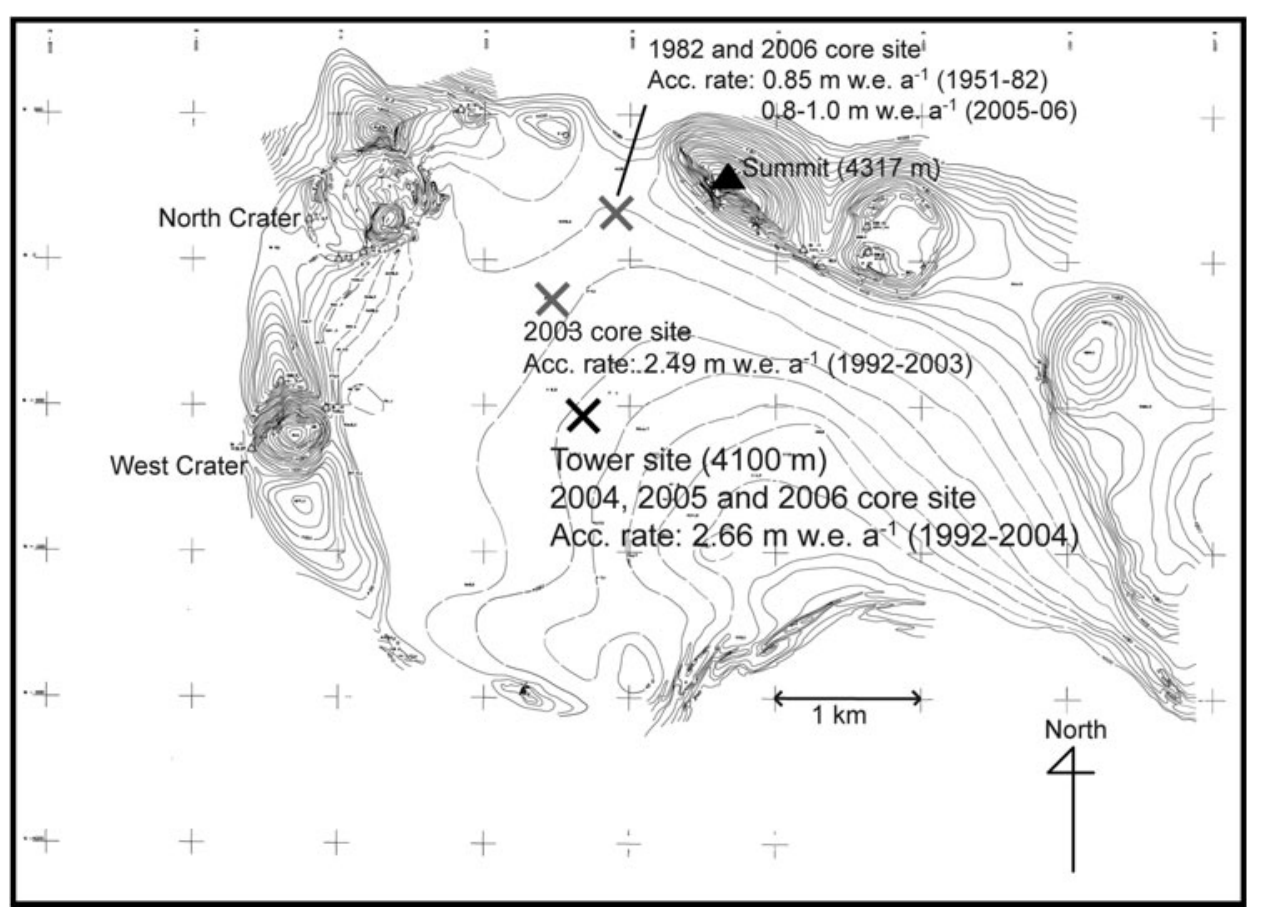

Fig. 2. Topographic map of the summit caldera, Mount Wrangell. The tower site and other two ice-core sites are shown with their average annual accumulation rates. Date of photogrammetry: 27 August 1975; contour interval: $10 \mathrm{~m}$.

August. In our study, half a year of daily accumulation and the total annual accumulation are covered by the measurements. The measured snow-accumulation history is compared with records from weather stations at the Pacific Coast (Fig. 1), which lie in the path of storms which affect Mount Wrangell, and a weather station in interior Alaska that is located in the mountain's rain shadow.

\section{OBSERVATION SITE}

Mount Wrangell has a broad summit area of $>35 \mathrm{~km}^{2}$ above $4000 \mathrm{~m}$ altitude and is dominated by a large, $4 \mathrm{~km} \times 6 \mathrm{~km}$, ice-filled summit caldera with post-caldera craters along its rim (Fig. 2). We observed the snow-accumulation rate at the center of the caldera, where an ice core was drilled to $216 \mathrm{~m}$ in 2004 and shallow ice cores were drilled in 2005 and 2006. The ice depth in the summit caldera is thought to exceed $900 \mathrm{~m}$, but a definite bottom has not yet been detected (Clarke and others, 1989; Benson and others, 2007). The altitude of the core site is $4100 \mathrm{~m}$. Glaciologically, the summit region is in the dry-snow facies. No significant melting occurs throughout the year. The $10 \mathrm{~m}$

Table 1. Annual precipitation of weather stations in south central Alaska

\begin{tabular}{lc} 
Site & $\begin{array}{c}\text { Annual precipitation } \\
\text { mm }\end{array}$ \\
& \\
\hline Gulkana & 290 \\
Yakutat & 4074 \\
Valdez & 1712 \\
Cordova & 2445
\end{tabular}

*US National Climate Data Center 30 year normal (1971-2000); Alaska Climate Summaries, http://www.wrcc.dri.edu/summary/climsmak.html deep temperatures at the Summit Caldera were $-20 \pm 0.5^{\circ} \mathrm{C}$ in the 1960s and in 1976 (Benson and Motyka, 1978), and $-18.9^{\circ} \mathrm{C}$ in a more recent study (Shiraiwa and others, 2004).

Annual accumulation rates are known at three points in the summit caldera from ice-core data. Figure 2 shows the locations and their annual accumulation rates. The dating of a tephra layer from the 1992 Mount Spurr eruption allowed a determination of average annual accumulation of 2.49 mw.e. (1992-2003) at the 2003 core site, which is located $0.7 \mathrm{~km}$ north-northwest from our study site (Yasunari and others, 2007). The same tephra layer was found at $52.6 \mathrm{~m}$ depth in the 2004 core, which results in an averaged accumulation rate of $2.66 \mathrm{~m}$ w.e. $(1992-2004)$ at the 2004 core site. Another $44 \mathrm{~m}$ long core was drilled in 1982 near the north rim of the summit caldera (Benson, 1984). This core was dated using the $\beta$-activity peak from nuclear tests in 1963 and annual-layer counting of stable-isotope ratios (C. Benson, unpublished data); the average accumulation rate was $0.85 \mathrm{~m}$ w.e. (1951-82). We also obtained a shallow surface core close to this site in 2006 . The accumulation rate was $0.8-1.0$ mw.e. (2005-06) according to annual-layer counting by stable-isotope ratio. The lower accumulation rate near the north rim seems to be caused by wind erosion, because of its exposed location in a pass. Aeolian surface features were evident at that site, whereas the surface was smooth at the center of the caldera. The accumulation measurements in this study were carried out at the 2004 core site, where accumulation rate was the highest. The effect of wind erosion is thought to be small at the site.

\section{METHODS}

\subsection{Accumulation}

In June 2005 we constructed a metal tower instrumented with temperature sensors so snow accumulation could be measured by noting the time when snow burial suppressed 

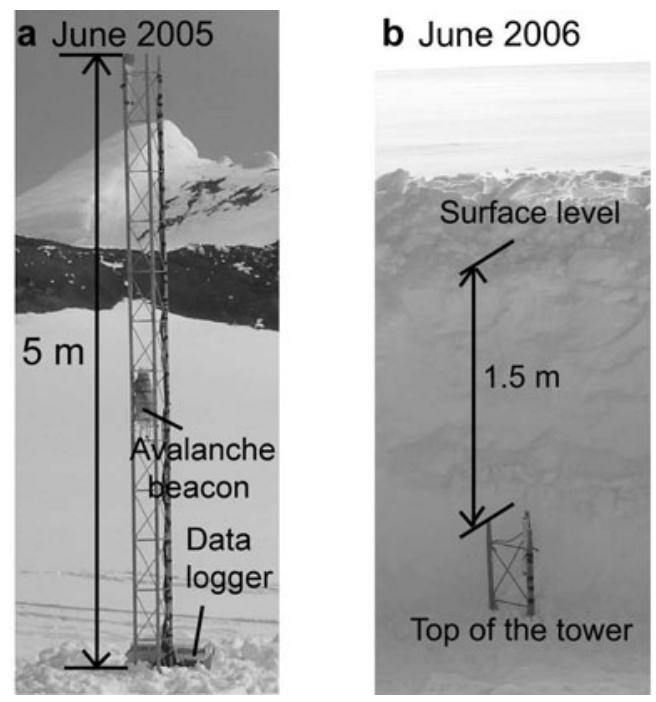

Fig. 3. Pictures of the accumulation measurement tower at the summit caldera of Mount Wrangell: (a) after installing the tower in June 2005; and (b) after 1 year of measurements in June 2006.

the diurnal temperature cycle. The conventional method of using an acoustic sounder to measure the distance between the snow surface and the sensor above the surface is unsuitable at Mount Wrangell because rime ice would disturb the sensor. A further problem is that rime ice and stormy weather at the summit may destroy the tower. To reduce the risk of collapse, only $5 \mathrm{~m}$ of the tower was left exposed above the snow surface in June 2005 (Fig. 3a). Although this was less than the expected annual accumulation of 6-7 m snow, it still covered most of the annual accumulation. Thirty-two sets of copper-constantan thermocouples were mounted on the tower at intervals of $0.15 \mathrm{~m}$, starting at $0.24 \mathrm{~m}$ above the 3 June snow surface. We recorded hourly temperatures with a CR-10X (Campbell Scientific Inc.) data logger and a multiplexer (AM16/32, Campbell Scientific Inc.). An internal sensor of the data logger measured the reference temperature for the thermocouples. The data logger and multiplexer were kept in an insulated box. The accuracy of each temperature measurement is within $\pm 1.5^{\circ} \mathrm{C}$. The temperature time series showed large variations in daily temperatures until they were buried by snow accumulation, which allowed the dates of burial to be determined. The detectable snow-height change by this method is $0.15 \mathrm{~m}$, and its time resolution is 1 day, because the suppression of the daily temperature cycle can only be detected within about 1 day. We also mounted an avalanche beacon (Ortovox, F-1 focus) at the middle of the tower, with additional batteries to help, in case of complete burial, to find the tower in the following year (Fig. 3a). We recovered the data in June 2006. At the time, the top of the tower was buried by $1.5 \mathrm{~m}$ of snow (Fig. 3b). To convert from snow depth to water-equivalent depth, we measured a density profile using a snow pit and ice cores to a depth of $8.3 \mathrm{~m}$ near the tower's location in June 2006.

\subsection{Weather-station data}

We used data from the weather stations Gulkana, Yakutat, Valdez and Cordova for comparison. All weather-station data used in this paper are from the US National Weather Service. The four stations we selected are the closest weather

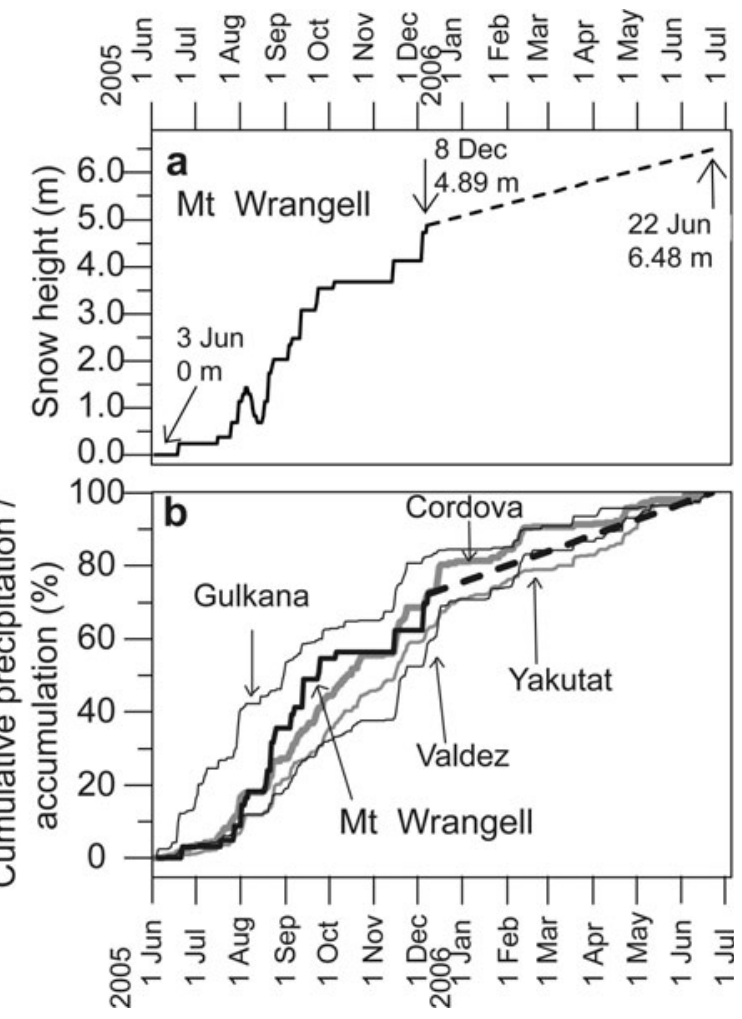

Fig. 4. Time-series data of accumulation at Mount Wrangell and precipitation at four weather stations in south central Alaska. (a) Snow height from 3 June 2005 to 22 June 2006 at the summit of Mount Wrangell. The top of the tower became buried on 8 December 2005. The dashed line shows the estimated value between burial of the tower and the snow surface of 22 June 2006, which was $6.48 \mathrm{~m}$ above the snow surface of 3 June 2005. (b) Cumulative accumulation at Mount Wrangell (thick black curve) and cumulative precipitation at four weather stations (Gulkana: thin black curve; Yakutat: thin gray curve; Valdez: thin black curve; Cordova: thick gray curve) in south central Alaska, from 3 June 2005 to 22 June 2006. See Figure 1 for the locations, and Table 1 for the annual precipitation rate. The values are expressed as a percentage of the total amount during the time period.

stations to Mount Wrangell. Table 1 shows their mean annual precipitation. Gulkana has much less precipitation than the three coastal stations because it is located in the precipitation shadow of the coastal mountains and the Wrangell-St Elias Mountains.

\section{RESULTS}

We obtained snow-height data from 3 June 2005 to 22 June 2006 (Fig. 4a). The thermocouples at 0.54, 2.79, 3.84 and $4.59 \mathrm{~m}$ above the initial snow surface had stopped working before they were buried by snow, but all others had sufficiently long records to determine the snow burial date. Total snow accumulation in the period was $6.48 \mathrm{~m}$ and the top of tower was buried by snow on 8 December 2005. Using the measured density profile, $6.48 \mathrm{~m}$ snow corresponded to $2.75 \mathrm{~m}$ w.e. The exact day of snow burial could be determined for $70 \%$ of the total accumulation. In mid-August 2005, the snow height temporarily decreased. This was due to snow compaction caused by melting. At that time, thermocouples that had been buried recorded an increase of snow temperature to the melting point. In addition, we found ice lenses at the corresponding depth when digging 


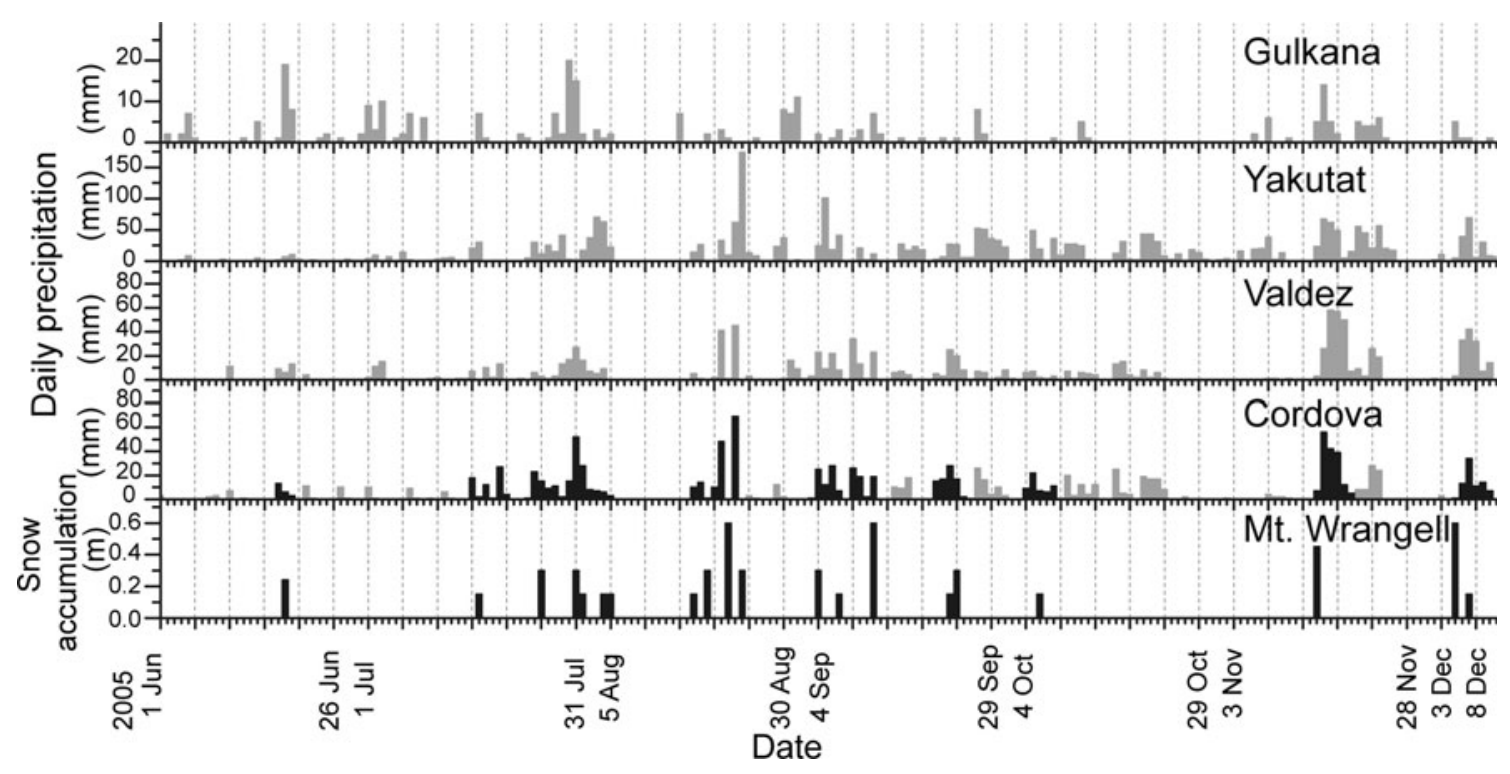

Fig. 5. Daily snow-accumulation rate at Mount Wrangell and daily precipitation rate at four weather stations in south central Alaska. Daily data at Mount Wrangell are unknown after 8 December. The coincident events on Mount Wrangell and Cordova are shown as black bars.

out the tower for data recovery, and in the ice core there was a $10 \mathrm{~mm}$ thick granular snow layer and two $2 \mathrm{~mm}$ thick ice lenses. This was the only event for which we found any surface lowering that exceeded the $0.15 \mathrm{~m}$ detection threshold.

Figure $4 \mathrm{~b}$ shows cumulative accumulation at Mount Wrangell and cumulative precipitation at the four weather stations. At Mount Wrangell, 50\% of the annual accumulation was observed in 2 months from the end of July to the end of September. Weather-station data at Cordova show a similar cumulative precipitation pattern. Despite the closer location of Gulkana, the fraction of the annual precipitation received from June to early August is much higher than at Mount Wrangell. Valdez and Yakutat data show a more gradual seasonal increase than Cordova. Both places had lower relative autumn precipitation and higher relative winter precipitation than Cordova and Mount Wrangell.

Figure 5 shows daily accumulation at Mount Wrangell that exceeded the detection threshold, and daily precipitation at the four weather stations. When Mount Wrangell

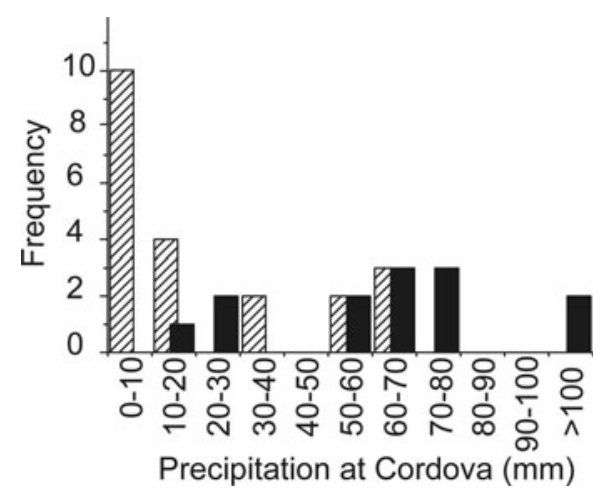

Fig. 6. Histograms of Cordova storm events from 3 June to 8 December 2005. The hatched bars show precipitation events that have no corresponding Mount Wrangell accumulation events. The black bars show precipitation events which occurred simultaneously with Mount Wrangell accumulation events. Accumulation events at Mount Wrangell always occurred simultaneously with Cordova precipitation events. had detectable snow-accumulation events, the weather stations also show precipitation events. This correspondence is particularly clear for Cordova and Valdez.

\section{DISCUSSION}

We compared precipitation events at Cordova and accumulation events at Mount Wrangell. Each continuous precipitation or accumulation event was regarded as one storm event. Some events which occurred with a 1 day interval between them at Mount Wrangell were counted as single events for comparison, because corresponding events at Cordova were continuous. From 3 June to 8 December 2005, there were 34 storm events at Cordova and 14 of these occurred simultaneously with storm events at Mount Wrangell (Fig. 5). Figure 6 shows a histogram of precipitation events at Cordova. Most of the storm events with $<20 \mathrm{~mm}$ precipitation had no corresponding accumulation event large enough to exceed the detection threshold on Mount Wrangell. However, all of the storm events with $>70 \mathrm{~mm}$ precipitation corresponded with recorded storm events on Mount Wrangell. Figure 7 shows a scatter plot of precipitation at Cordova and accumulation at Mount Wrangell for each corresponding storm event. The data show a positive dependency, but poor linear correlation $(r=0.29)$; it is therefore difficult to estimate the amount of accumulation during individual storms on Mount Wrangell from Cordova precipitation. To evaluate the relationship for longer periods, we compared annual accumulation time series from ice-core datasets from 1992 to 2002 (Yasunari and others, 2007) with annual precipitation time series at Cordova. Yasunari and others (2007) dated the ice core using five seasonal peaks in multi-parameters such as dust peaks in early spring, tritium maxima in late spring, stable-isotope ratio maxima in summer, tritium minima in autumn and stable-isotope minima in winter. Because each seasonal peak had some error in matching it to a calendar date, five patterns of annual accumulation time series, each dividing the seasonal peaks, were examined for monthly annual precipitation data. The correlations are shown in Figure 8. 


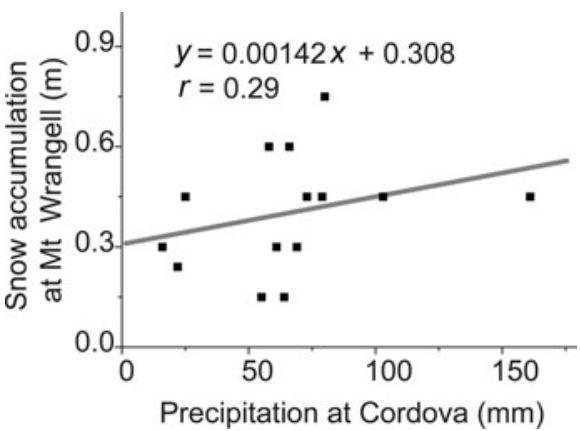

Fig. 7. Scatter plot of coincidence storm events at Cordova and Mount Wrangell. The gray line is the regression line of the plot.

The best correlation is a combination of annual accumulations determined by early-spring peaks and annual precipitation divided by August precipitation, which has a correlation coefficient of 0.57 . The correlation coefficients vary widely and there is a time lag of several months for the best correlation in each ice-core dataset. If there is a simple linear relation between the two sites, the best correlation should appear with no time lags. It appears that complications in the correlations make it difficult to estimate the amount of accumulation at the summit of Mount Wrangell from Cordova precipitation data on an interannual scale. The errors in dating ice cores are still too large to enable direct comparison with calendar dates. Also, the relationship between a lower coastal site and the summit of Mount Wrangell may have interannual variation; Dettinger and others (2004) showed that storms during a La Niña winter tend to bring heavier precipitation at higher altitudes in the Sierra Nevada, California, USA.

At the summit of Mount Wrangell, snow accumulation was highest from late summer to autumn during the year from June 2005 to June 2006 (Fig. 4b). The seasonal accumulation pattern observed at the summit of Mount Wrangell is similar to the seasonal precipitation pattern at Cordova during the same year. The 2005/06 year seems to have a normal seasonal precipitation distribution at Cordova. Figure 9 shows the net 30 year average of the monthly precipitation fraction from June 1972 to May 2005 in Cordova and the fraction from June 2005 to May 2006. Although monthly fractions were different from January to May, higher precipitation from late summer to autumn (August to October) is common. It is therefore reasonable to assume that the normal precipitation pattern at Mount Wrangell also follows this pattern.

Our records indicate that some of the accumulation occurs during large episodic events. We detected 17 such events at the summit of Mount Wrangell between June and December 2005, 7 of which produced $>0.45 \mathrm{~m}$ of snow accumulation (Fig. 5). This suggests that Mount Wrangell ice cores largely reflect high-precipitation events by large storms. Such seasonality in accumulation rate or episodic accumulation events would occur at other ice-core sites such as those shown in Figure 1. Similar studies would greatly aid ice-core interpretation at the other sites by demonstrating the timing of what is actually being recorded in the ice core.

In a previous study that relates snow accumulation at Mount Logan to local climate, Rupper and others (2004) demonstrated that only winters in a high-accumulation year

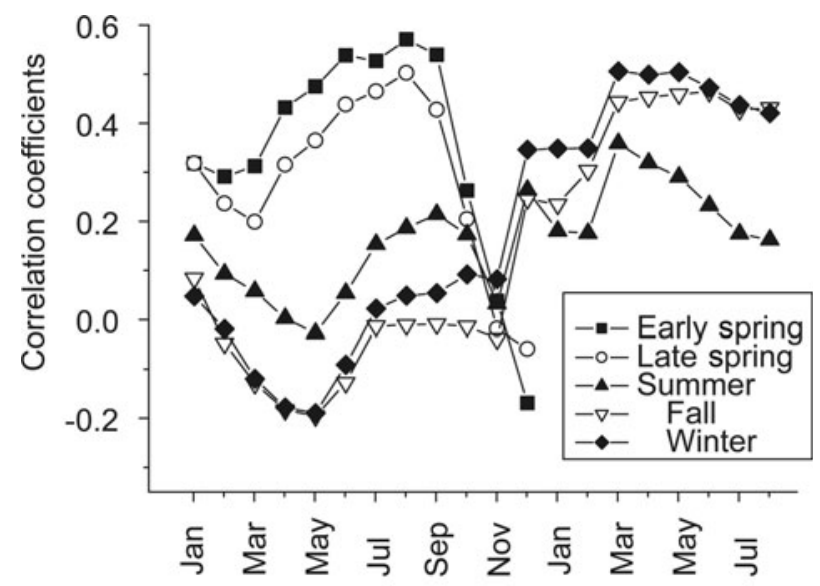

Divisions of annual precipitation data at Cordova

Fig. 8. Correlation coefficients between five patterns of annual accumulation time series at Mount Wrangell (1992-2002) and annual precipitation time series at Cordova (1992-98, 2000-02). The Cordova data were examined for monthly lagged time series from January to August in the following year.

have a robust connection with atmospheric circulation. The observed year at Mount Wrangell is an average accumulation year. However, there still appears to be a simple relationship between snow accumulation at Mount Wrangell and precipitation at Cordova. We speculate that most of the precipitation at Mount Wrangell is preserved after deposition without significant wind erosion, which might not be the case in a col location such as Mount Logan or the 1982 core site on Mount Wrangell. The direct relationship between accumulation on a mountain and precipitation at a sea-level weather station, lying upwind during storms, may be characteristic of Mount Wrangell only. Snow accumulation at Mount Wrangell seems to reflect regional weather systems at a synoptic scale rather than local convective activity which might be expected for a mountain site.

\section{CONCLUSIONS}

We conducted an experiment to determine snow accumulation during individual storms in the summit caldera of Mount Wrangell. The method using temperature sensors was

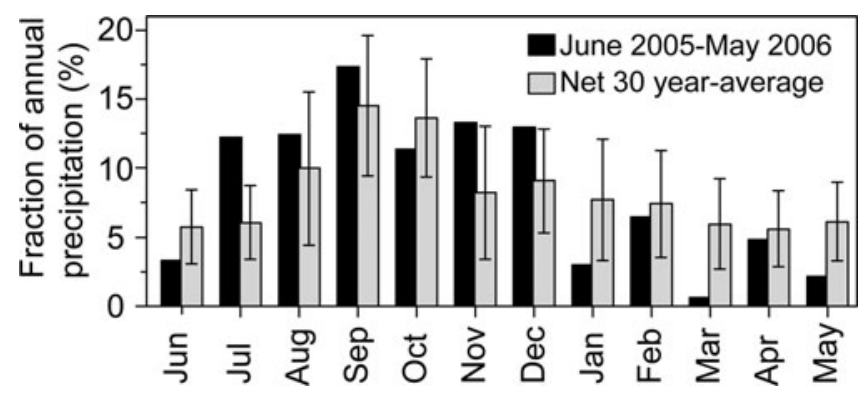

Fig. 9. Comparison of monthly precipitation in the observation year (June 2005 to May 2006) with the 30 year average at Cordova. The error bars show standard deviations. The monthly values are expressed as percentages of the annual precipitation for each year. The net 30 year average is calculated with the data from June 1972 to May 2005. The data of 1985, 1990 and 1999 were excluded because there are some missing values in the original precipitation record. 
simple and effective in a harsh environment. The main accumulation season at the summit of Mount Wrangell is from late summer to autumn. In our observation period from June 2005 to June 2006, we found that 50\% of annual accumulation occurred in late summer to autumn. This seasonal accumulation pattern was similar to the precipitation pattern of Cordova, which is one of the closest Pacific coastal weather stations to Mount Wrangell. Most of the accumulation events seemed to originate from storms that also caused relatively high precipitation in Cordova. A meaningful interpretation of the Mount Wrangell ice core will need to consider the seasonality and episodic nature of the accumulation. The experiment described in this paper demonstrates that individual storms at the summit of Mount Wrangell could be matched with individual storms recorded at sea level for half a year. Results suggest that snow accumulation at Mount Wrangell reflects synoptic-scale, regional weather systems rather than localized convective activity. Such an accumulation measurement has not been made before; it gives new data for the analysis of pit and core studies at various places in the extensive and complex summit region of Mount Wrangell.

\section{ACKNOWLEDGEMENTS}

This work was supported by the Sasakawa Scientific Research Grant from The Japan Science Society and Grants-in-Aid for Creative Scientific Research (No. 14GS0202) and Basic Research B (No. 16403005) from the Japanese Ministry of Education, Culture, Sports, Science and Technology. We thank Y. Kodama who suggested the snow-accumulation measurement and M. Shulski who helped in the acquisition of weather-station data. We also thank A. Sterns and F. Olive for enthusiastic assistance with the fieldwork.

\section{REFERENCES}

Benson, C.S. 1968. Glaciological studies on Mount Wrangell, Alaska, 1961. Arctic, 21(3), 127-152.

Benson, C.S. 1984. Ice core drilling on Mt. Wrangell, Alaska, 1982. CRREL Spec. Rep. 84-34, 61-68.

Benson, C.S. and R. Motyka. 1978. Glacier-volcano interactions on Mt. Wrangell, Alaska. In Geophysical Institute Annual Report 1978. Fairbanks, AK, University of Alaska, 1-25.
Benson, C.S., R.J. Motyka, S. McNutt, M. Lüthi and M. Truffer. 2007. Glacial-volcano interactions in the North Crater of Mt Wrangell, Alaska. Ann. Glaciol., 45, 48-57.

Clarke, G.K.C., G.M. Cross and C.S. Benson. 1989. Radar imaging of glaciovolcanic stratigraphy, Mount Wrangell caldera, Alaska: interpretation model and results. J. Geophys. Res., 94(B6), 7237-7249.

Dettinger, M., K. Redmond and D. Cayan. 2004. Winter orographic precipitation ratios in the Sierra Nevada: large-scale atmospheric circulations and hydrologic consequences. J. Hydromet., 5(6), 1102-1116.

Fisher, D.A. and 20 others. 2004. Stable isotope records from Mount Logan, Eclipse ice cores and nearby Jellybean Lake. Water cycle of the North Pacific over 2000 years and over five vertical kilometers: sudden shifts and tropical connections. Géogr. Phys. Quat., 58(2-3), 337-352.

Goto-Azuma, K. and 6 others. 2003. An overview of the Japanese glaciological studies on Mt. Logan, Yukon, Territory, Canada in 2002. Bull. Glaciol. Res., 20, 65-72.

Holdsworth, G., H.R. Krouse and M. Nosal. 1992. Ice core climate signals from Mount Logan, Yukon, AD 1700-1987. In Bradley R.S. and P.D. Jones, eds. Climate since $A D 1500$. London, Routledge, 483-504.

Partington, K.C. 1998. Discrimination of glacier facies using multitemporal SAR data. J. Glaciol., 44(146), 42-53.

Rupper, S., E.J. Steig and G. Roe. 2004. The relationship between snow accumulation at Mt. Logan, Yukon, Canada, and climate variability in the North Pacific. J. Climate, 17(24), 4724-4739.

Shiraiwa, T., S. Kanamori, C.S. Benson, D. Solie and Y.D. Muravyev. 2004. Shallow ice-core drilling at Mount Wrangell, Alaska. Bull. Glaciol. Res., 21, 71-78.

Steig, E.J., P.M. Grootes and M. Stuiver. 1994. Seasonal precipitation timing and ice core records. Science, 266(5192), 1885-1886.

Wharton, G.B., Jr. 1966. Snow stratigraphy studies in the caldera at the summit of Mt Wrangell, Alaska. (MSc thesis, University of Alaska Fairbanks.)

Yalcin, K., C.P. Wake, K.J. Kreutz and S.I. Whitlow. 2006. A 1000-yr record of forest fire activity from Eclipse Icefield, Yukon, Canada. Holocene, 16(2), 200-209.

Yasunari, T.J. and 7 others. 2007. Intra-annual variations in atmospheric dust and tritium in the North Pacific region detected from an ice core from Mount Wrangell, Alaska. J. Geophys. Res., 112(D10), D10208. (10.1029/2006JD008121.)

Zagorodnov, V., L.G. Thompson, P. Ginot and V. Mikhalenko. 2005. Intermediate-depth ice coring of high-altitude and polar glaciers with a lightweight drilling system. J. Glaciol., 51(174), 491-501. 